
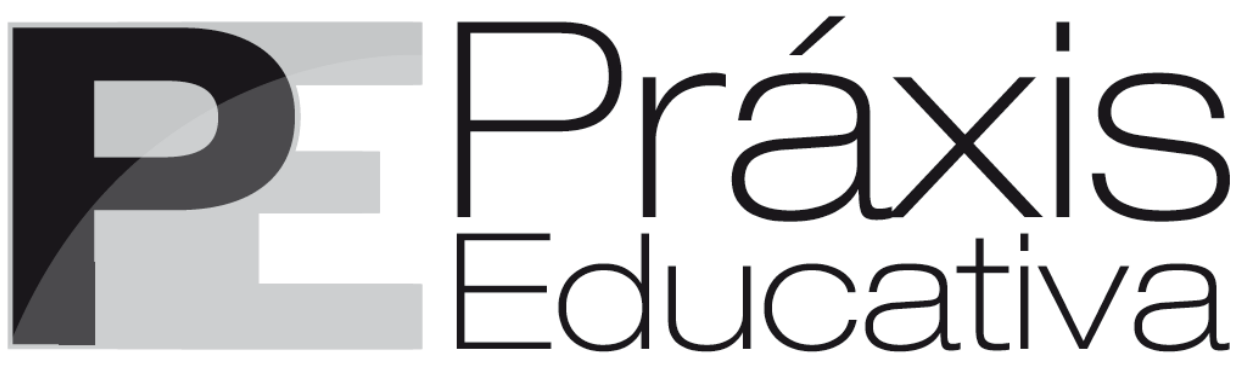

ISSN 1809-4309 (Versão online) DOI: 10.5212/PraxEduc.v.11i3.0001

Apresentação

\title{
Dossiê: Políticas de Avaliação e Currículo
}

A revista Práxis Educativa publica neste número o dossiê: Políticas de Avaliação e Currículo composto por dezesseis artigos e duas resenhas. O objetivo do dossiê foi ampliar a discussão sobre as influências das políticas de avaliação sobre os currículos da Educação Básica e da Educação Superior.

O conjunto de artigos que integram o dossiê aborda temas sobre as políticas de avaliação e as suas implicações nos currículos escolares a partir de diferentes perspectivas teóricas. Traz à tona a necessidade de se empreender esforços para romper com a perspectiva de controle, medida, classificação, responsabilização e exclusão que tais políticas vêm assumindo nos contextos educacionais, tanto nacionais como internacionais, ao serem tomadas como definidoras das políticas educativas e curriculares, da gestão dos sistemas de ensino e das escolas, dos currículos, das práticas docentes e, consequentemente, da aprendizagem dos estudantes.

O primeiro subconjunto de artigos do dossiê é composto por três ensaios teóricos que abordam o tema da avaliação educacional relacionado à discussão sobre: direito de aprender e a qualidade da educação; relações entre currículo e avaliações em larga escala; políticas de avaliação e currículo no espaço ibero-americano. O primeiro, intitulado Políticas públicas: direito de aprender e avaliaşão formativa, de autoria de Antonio Chizzotti, discute o direito de aprender no ensino de tipo escolar e considera a avaliação formativa como uma das garantias de qualidade do ensino e da aprendizagem. Ele trata dos processos avaliativos correntes e dos equívocos discriminatórios de avaliações meramente somativas, tendencialmente classificatórias dos alunos. O segundo, Sobre Foucault e a verdade: as relações entre currículo e avaliações em larga escala, escrito por Rosimar Serena Siqueira Esquinsani e Jarbas Dametto, apresenta resultados de uma pesquisa de base documental e bibliográfica, cujo escopo incide sobre a noção de "verdade" em Michel Foucault, salientando em suas conclusões que as avaliações em larga escala são capazes de moldar o currículo escolar, impondo-se como porta-voz da verdade em relação ao projeto de sociedade em pauta. O terceiro texto, Políticas de currículo e avaliação para a docência no espaço Iberoamericano, de Rosanne Evangelista Dias, analisa os processos de articulação discursiva presentes nos textos da Organização dos Estados Iberoamericanos - OEI e da UNESCO, destacando o significante desempenho como foco da avaliação e concluindo que as tentativas de controle sobre a comunidade profissional docente na sua formação e trabalho projetam novos papéis para o professor, que são marcados pela responsabilização. 
Dois artigos compõem o segundo subconjunto de textos do dossiê, os quais são oriundos de pesquisas com coordenadores de cursos de graduação. O primeiro, intitulado As posições-sujeito (Estado e gestores) diante das avaliaçoes em larga escala no Ensino Superior brasileiro, de autoria de Taise Feldmann, Osmar de Souza e Marcia Regina Selpa Heinzle analisa as posições-sujeito do Estado e dos coordenadores de cursos de graduação a fim de compreender as influências das políticas de avaliação nos currículos da Educação Superior. Os resultados da investigação apontam que tais posições são interpeladas tanto pelos efeitos ideológicos do Estado, quanto pela posição-sujeito de coordenador/gestor de curso e produzem efeitos de sentido de acatamento, regulação e/ou controle e resistência e/ou descontentamento. O segundo, escrito por Silvia Regina Canan e Vanessa Taís Eloy, tem por título Políticas de avaliaşão em larga escala: o ENADE interfere na gestão dos cursos? e analisa como os gestores (coordenadores) dos cursos de graduação avaliam o ENADE enquanto política de avaliação em larga escala e de que estratégias de gestão lançam mão para melhorar a avaliação dos cursos. A pesquisa revelou que grande parcela dos coordenadores entrevistados está buscando novas possibilidades para qualificar os cursos, contudo, ainda são tentativas isoladas e muito subjetivas; a preocupação com resultados quantitativos é muito forte, sobrepondo-se aos processos qualitativos; o ENADE, como avaliação em larga escala, não está conseguindo desencadear um processo profundo de discussão teórica.

As políticas de avaliação em larga escala e suas implicações nos currículos escolares da Educação Básica constituem o terceiro subconjunto de artigos deste dossiê, constituído por onze textos. O artigo de Rita de Cássia Silva Godoi Menegão, Os impactos da avaliação em larga escala nos currículos escolares, abre o terceiro subconjunto de textos desse dossiê. A autora analisa o currículo escolar na interface com a avaliação externa com os objetivos de identificar, descrever e analisar como os sujeitos estão se posicionando nesse contexto de testes e mapear as alterações realizadas no currículo escolar, impelidas pela Prova Brasil e IDEB. Os resultados da pesquisa evidenciaram que a avaliação externa tem impactado a configuração do currículo escolar e induzido em demasia ao treinamento para os testes, comprometendo, desta forma, a qualidade da educação. Os sentidos do SARESP para professores e alunos da rede pública estadual paulista e a gestão do currículo na sala de aula, artigo dos autores Renata Cristina Oliveira Barrichelo Cunha, Andreza Barbosa, Natiely Pasetto e Silva e Daniela Aparecida Lando, discute os efeitos das avaliações externas na gestão do currículo na sala de aula e, a partir da análise dos dados, a pesquisa constatou que o SARESP pode ser considerado como parâmetro e referência para a reflexão e ajustes no planejamento dos professores, mas a centralidade que assumiu na organização do trabalho pedagógico está caracterizada como medida e controle. O texto Política de Avaliação do Estado do Rio de Janeiro: repercussões na gestão escolar e no currículo, dos autores Leonardo Meirelles Cerqueira, Wânia Gonzalez e Elisangela da Silva Bernado, discute o sistema de avaliação do estado do Rio de Janeiro a partir da década de 1990: o "SAERJ" e o "Saerjinho", o Currículo Mínimo, o Sistema on-line chamado Conexão e o "IDERJ", a partir dos quais foi possível identificar uma política avaliativa fortemente marcada por responsabilizar os professores e diretores pelos resultados alcançados pelas escolas. Em sintonia com o texto anterior, o artigo Conbecimento histórico escolar: fixações de sentidos a partir de uma política de avaliação no Rio de Janeiro, de Marcus Leonardo Bomfim Martins e Carmen Teresa Gabriel, problematiza as disputas por fixação de sentidos de conhecimento histórico escolar no Saerjinho - instrumento avaliativo que compõe o sistema de avaliação da rede fluminense. As análises apontaram que não há disputas pelo que do conhecimento histórico fixado, mas pelo quem tem o direito de fixar tal conhecimento em um instrumento avaliativo.

Gabriela Pereira da Cunha Lima e Cláudio Lúcio Mendes, no artigo Currículo, avaliação e a constituição do sujeito docente, analisam de modo articulado o dispositivo curricular do Estado de Minas - Conteúdos Básicos Comuns (CBC) e o dispositivo avaliativo a ele atrelado - Sistema Mineiro de Avaliação da Educação Pública (SIMAVE) a partir da compreensão de que as práticas neoliberais presentes no Estado e na sociedade enquadram o currículo e a avaliação sob a ótica da economia.

Práxis Educativa, Ponta Grossa, p. 557-560, v. 11, n. 3, set./dez. 2016 Disponível em: <http://www.revistas2.uepg.br/index.php/praxiseducativa> 
Os autores concluíram que a partir da articulação entre o CBC e o SIMAVE atuam práticas de mercado gerenciais e performáticas por meio de uma série de poderes e saberes que a ela estão associados, tornando as propostas curriculares supostamente indissociáveis dessas práticas e dos processos de subjetivação dos docentes. No texto, Política de Avaliação e Programa de Educaşão Integral no Ensino Médio da Rede Estadual de Pernambuco: os limites da centralidade da avaliação nas políticas educacionais, Katharine Ninive Pinto Silva e Jamerson Antonio de Almeida da Silva, avaliam a relação entre a Política de Responsabilidade Educacional, a Política de Avaliação definida pela Rede Estadual de Pernambuco e o processo de implementação do Programa de educação Integral (PEI) nas Escolas de Referência em Ensino Médio (EREMs) e nas Escolas Técnicas Estaduais (ETEs). Os autores da pesquisa concluíram que estratégias como o aumento dos anos de estudo e da jornada escolar camuflam problemáticas como a crise do desemprego estrutural e a diminuição dos investimentos previstos nas políticas sociais como um todo. Políticas de avaliação na educação básica e seus desdobramentos na disciplina de Arte, texto de Silvia Sell Duarte Pillotto e Jane Mery Richter Voigt, apresenta os resultados de uma pesquisa que identificou como professores da disciplina de Arte se apropriaram das políticas de avaliação e quais foram os desdobramentos dessas políticas nas práticas educativas desses profissionais. A análise dos resultados apontou fragilidades no entendimento dos professores sobre os critérios avaliativos, suas conexões com o ensino e aprendizagem e quais políticas de avaliação são assumidas pela escola. Elma Júlia Gonçalves de Carvalho e Jane Eire Rigoldi Santos, no artigo Politicas de avaliações externas: ênfase nas competências cognitivas e socioemocionais, apresentam uma análise dos objetivos, dos fundamentos e das matrizes de referência da Prova Brasil e o Projeto SENNA, relacionando-os às novas exigências do capital e aos direcionamentos das organizações internacionais a partir dos anos de 1990. Os resultados apontam que a lógica das competências corresponde a uma tendência nos direcionamentos políticos e pedagógicos de negação dos conhecimentos científicos e culturais e do papel da escola como responsável pela distribuição, o mais igualmente possível, dos conhecimentos sistematizados. Maria Carolina da Silva Caldeira e Marlucy Alves Paraíso, no artigo Avaliações no currículo do primeiro ano do Ensino Fundamental: governo de professores/as e alunos/as e implementação do dispositivo de antecipação da alfabetização analisam os efeitos de avaliações em um currículo de uma turma de primeiro ano do Ensino Fundamental e mostram a lógica avaliativa em ação no currículo que faz a avaliação assumir três formas: 1) avaliação para acompanhar a aprendizagem das crianças; 2) avaliação dos comportamentos infantis; 3) avaliações sistêmicas. Os resultados apontam que esses três modos de avaliar, com suas diferentes estratégias e práticas, conduzem os mais diferentes raciocínios no currículo investigado. A conclusão é de que são instituídas relações de poder-saber, governando alunos/as e docentes e auxiliando na implementação e operacionalização do dispositivo de antecipação da alfabetização.

O artigo, Avaliação e Currículo na Educação Básica: a especificidade da Educação Infantil, escrito por Maria Nilceia Andrade Vieira e Valdete Côco, apresenta discussões sobre a avaliação institucional e o currículo na/da Educação Infantil. Os resultados evidenciam que a sustentação teórica e o embasamento legal da Educação Infantil, no que tange à avaliação e ao currículo, fortalecem um percurso de consolidação de seu pertencimento à Educação Básica em simultaneidade à demarcação de sua especificidade. A avaliação na Educação Infantil: uma análise a partir de relatórios de uma professora, de autoria de Gabriela Medeiros Nogueira e Gabriela Ortiz Prado, apresenta resultados de uma pesquisa que analisou os relatórios de avaliação de uma professora de Escola Municipal Educação Infantil em Rio Grande (RS) a fim de diagnosticar a concepção de avaliação presente na educação infantil, Os resultados indicam uma perspectiva de avaliação mais focada no trabalho do professor do que nas crianças, evidenciando propostas e resultados, sem enfatizar o percurso de desenvolvimento de cada criança.

Encerrando o dossiê, há duas resenhas: a primeira, elaborada por Viviane Grimm, Fernando Cesar Sossai e Marília Segabinazzi, sobre o livro de BALL, Stephen Ball: Educação Global

Práxis Educativa, Ponta Grossa, p. 557-560, v. 11, n. 3, set./dez. 2016 Disponível em: <http://www.revistas2.uepg.br/index.php/praxiseducativa> 
S. A.: novas redes de políticas e o imaginário neoliberal, publicado pela Editora UEPG em 2014, o qual traz uma excelente contribuição do autor sobre políticas educacionais na atualidade face a globalização, as redes políticas e o neoliberalismo; a segunda, elaborada por Bruna Mayara Bonatto e Graciete Tozetto Góes, da obra Sobre notas escolares: distorções e possibilidades, de Cipriano Carlos Luckesi, publicada em 2014 pela editora Cortez, indica que o livro traz uma análise aprofundada sobre as notas escolares e como seu uso distorcido e equivocado prejudica a busca pela "qualidade plena" na educação.

Enfim, desejo que a leitura dos textos deste dossiê contribua para reflexões e avanços nas pesquisas sobre políticas de avaliação e currículo ao mesmo tempo em que inspirem os formuladores e gestores de políticas educacionais, voltadas à Educação Básica e Educação Superior, a considerar a avaliação em suas diferentes dimensões, integrada aos processos educativos, a partir de concepções avaliativas mais inclusivas, democráticas e emancipatórias.

Aos autores, pareceristas, revisores e à comissão editorial da revista Práxis Educativa, agradeço pelas valiosas contribuições e singular competência e parceria que tornaram possível a concretização deste dossiê.

\author{
Mary Ângela Teixeira Brandalise \\ Editora Convidada
}

